\title{
Teamwork and collaboration among doc- tors and nurses in two public hospitals in China
}

\author{
H Xu ${ }^{1}, \mathrm{~F} \mathrm{Li}^{2}, \mathrm{~J}$ M Johnston ${ }^{1}$ \\ 1 School of Public Health, The University of Hong Kong \\ ${ }_{2}$ Guangzhou $8^{\text {th }}$ People Hospital
}

\begin{abstract}
The Work-related Collaboration among Doctor-Nurse Scale (WCDNS) was administered to 398 doctors and nurses working in one of two hospitals in Guangzhou to assess 1) inter professional (doctor-nurse) differences in collaboration and teamwork and 2) inter hospital (general-specialist) differences in doctor nurse collaboration. Significant between profession and hospital differences were observed. Implications for future studies in doctor-nurse collaboration are discussed.
\end{abstract}

Keywords: collaboration, doctor, nurse, public hospital, China

\section{Introduction}

Although historically, hierarchical working relationships have characterized doctor and nurse communication during the past decade, more collaborative relationships have become more commonplace, especially, in hospital ${ }^{[1,2]}$. However, as the professional goals of doctors and nurses differ - clinical care delivery and patient care and advocacy - they face challenges in collaboration ${ }^{[3]}$.

\section{Aims}

This study aimed to assess doctor - nurse willingness to collaborate and the impact of hospital type on doctor - nurse collaboration.

\section{Methods}

\subsection{Setting and participants}

All the eligible doctors $(\mathrm{N}=156)$ and nurses $(\mathrm{N}=325)$ were recruited. The human resources department provided to the unblinded research assistant a list of all doctors and nurses on staff.

\subsection{Study instruments}

The 26-item Work Related Collaboration among Doctor-Nurse Scale (WCDNS) adopts a 4-point Likert-type scale (4= strongly agree, $3=$ agree, $2=$ disagree, $1=$ strongly disagree) with a scoring range of 26-104, where a higher total score means a more positive attitude toward collaboration. The scale has three factors: work related autonomy, work related skills and work related relationships, was translated and validated in two Chinese public hospitals in 2013. It has good construct and content validity (Cronbach's alpha $=0.83$ ), and a test-retest reliability was conducted $(\mathrm{ICC}=0.87)$. 


\subsection{Process}

Questionnaires were administered to all eligible doctors and nurses during the ward morning meeting. If a subject could not be identified in one of 5 consecutive morning meetings they were removed from the recruitment pool. The questionnaire took approximately 20 minutes to complete.

\subsection{Data analysis}

Confirmatory factor analysis was used to extract the WCDNS domains. T-test and ANOVA were used to test the associations between the demographic characteristics, work-related collaborative scale domains and hospital characteristics. The Statistical Package for Social Sciences 19.0 was used for data analysis.

\section{Results}

Three WCDNS factors were extracted, each with an Eigen value greater than 1.0, "Work-related Autonomy", (10 items, explained $27.1 \%$ of total variance Cronbach's Alpha $=0.71)$, "Work-related skills" (10 items, explained $23.3 \%$ of total variance Cronbach's Alpha $=0.88$ ), and "Work-related Relationships" (6 items, $15.9 \%$ of total variances Cronbach's Alpha $=0.73$ ).

The subject characteristics differed by hospital type. The general hospital staff were slightly younger, more likely to be single and have less work experience and to be junior staff (Table 1).

The overall WCDNS mean score for nurses is higher (greater collaboration and teamwork) than for doctors (83.17 vs. 74.28; $\mathrm{p}<0.001)$ and by hospital type was higher for the general (JGH) than the specialist hospital (DH) (84.17 vs. 77.28, $\mathrm{p}<0.001)$. For three domains, the mean scores were higher for the general (Table 2).

\begin{tabular}{|c|c|c|c|}
\hline & $\begin{array}{l}\text { Specialist } \\
\text { hospital } \\
(\mathbb{N}=187)\end{array}$ & $\begin{array}{l}\text { General } \\
\text { hospital } \\
(\mathrm{N}=211)\end{array}$ & $\begin{array}{c}\text { Total } \\
\mathrm{N}=398(\%)\end{array}$ \\
\hline \multicolumn{4}{|l|}{ Gender } \\
\hline Male & $22(11.8)$ & $38(18.0)$ & $60(15.1)$ \\
\hline Female & $165(88.2)$ & $173(82.0)$ & $338(84.9)$ \\
\hline \multicolumn{4}{|l|}{ Age group } \\
\hline $21-30$ & $84(44.9)$ & $114(54.0)$ & $198(49.8)$ \\
\hline $31-35$ & $46(24.6)$ & $43(20.4)$ & $89(22.4)$ \\
\hline $36-<40$ & $57(30.5)$ & $54(25.6)$ & $111(27.8)$ \\
\hline \multicolumn{4}{|l|}{ Marital status } \\
\hline Single & $71(37.9)$ & $104(49.3)$ & $175(44.0)$ \\
\hline Married & $116(62.1)$ & $107(50.7)$ & $223(56.0)$ \\
\hline \multicolumn{4}{|l|}{ Working years } \\
\hline$<1-3$ & $65(34.7)$ & $150(71.1)$ & $215(54.0)$ \\
\hline $4-9$ & $30(16.0)$ & $19(9.0)$ & $49(12.3)$ \\
\hline$<10$ & $92(49.3)$ & $42(19.9)$ & $134(33.7)$ \\
\hline \multicolumn{4}{|l|}{ Income } \\
\hline $2500-3500$ & $85(45.5)$ & $95(45.0)$ & $180(45.2)$ \\
\hline $3501-5500$ & $63(33.7)$ & $75(35.5)$ & $138(34.7)$ \\
\hline $5501-7500$ & $39(20.8)$ & $41(19.5)$ & $80(20.1)$ \\
\hline \multicolumn{4}{|l|}{ Employment } \\
\hline Permanent & $81(43.3)$ & $97(45.9)$ & $178(44.7)$ \\
\hline Contract & $106(56.7)$ & $114(54.1)$ & $220(55,3)$ \\
\hline \multicolumn{4}{|l|}{ Working title } \\
\hline Senior doctor/nurse & $27(14.4)$ & $20(9.5)$ & $47(11.8)$ \\
\hline Junior doctor nurse & $160(85.6)$ & $191(90.5)$ & $351(88.2)$ \\
\hline
\end{tabular}

Table 1 Sample Characteristics by overall and hospital type

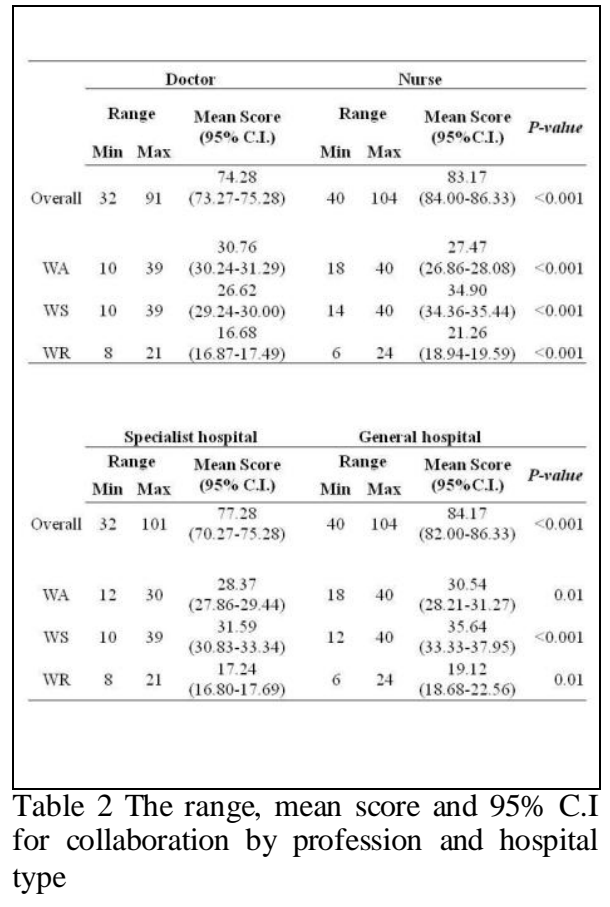




\section{Discussion}

The confirmatory factor analysis was satisfactory. The more positive attitudes among the nursing staff is consistent with teamwork and collaborative work done elsewhere ${ }^{[4-6]}$. The variation in collaborative working relationships by hospital type (lower in specialist) may be explained by the general staff shortage in hospitals in China and greater work related stress and demand in specialist hospitals ${ }^{[7]}$. Further research is needed to identify other potential factors contributing to reduced work-related collaboration by hospital type.

\section{Conclusion}

Improved collaborative working relationships have been shown elsewhere to benefit patient care, health related outcomes and staff satisfaction...Given the potential growing healthcare burden in China with rising expectations for improved quality of care and an ageing population it is incumbent on health care managers to ensure the best patient related outcomes as well as high efficiency gains in healthcare delivery.

\section{References}

[1] Baggs JG. Development of instruments to measure the collaboration and satisfaction about care decisions. Journal of Advanced Nursing, 1994: 20; 176-182.

[2] Fagin CM. Collaboration between nurses and physicians: no longer a choice. Academic Medicine. 1992;67(5):295-303.
[3] Hojat M, Gonnella, JS, Nasca, Thomas J, Fields, SK, Cicchetti, Americo, Scalzo. Comparisons of American, Israeli, Italian and Mexican physicians and nurses on the total and factor scores of the Jefferson scale of attitudes toward physician-nurse collaborative relationships. International Journal of Nursing Studies, 2003: 40(4); 427-435.

[4] McGrail, K. A., Morse, D. S., Glessner, T., \& Gardner, K. (2009). "What is found there": qualitative analysis of physician-nurse collaboration stories. Journal of General International Medicine, 24(2), 198-204.

[5] O'Brien, J. L., Martin, D. R., Heyworth, J. A., \& Meyer, N. R. (2009). A phenomenological perspective on advanced practice nurse-physician collaboration within an interdisciplinary healthcare team. Journal of American Academic Nurse Practice, 21(8), 444-453.

[6] Rice, K., Zwarenstein, M., Conn, L. G., Kenaszchuk, C., Russell, A., \& Reeves, S. (2010). An intervention to improve interprofessional collaboration and communications: a comparative qualitative study. Journal of Interprofessional Care, 24(4), 350-361.

[7] Shen, H. C., Chiu, H. T., Lee, P. H., Hu, Y. C., \& Chang, W. Y. (2011). Hospital environment, nurse-physician relationships and quality of care: questionnaire survey. Journal of Advanced Nursing, 67(2), 349-358. 